\title{
Vmat2 Heterozygous Mutant Mice Display a Depressive-Like Phenotype
}

\author{
Masato Fukui, ${ }^{1}$ Ramona M. Rodriguiz, ${ }^{1}$ Jiechun Zhou, ${ }^{1}$ Sara X. Jiang, ${ }^{1}$ Lindsey E. Phillips, ${ }^{1}$ Marc G. Caron, ${ }^{2}$ and \\ William C. Wetsel ${ }^{1,3}$ \\ ${ }^{1}$ Department of Psychiatry and Behavioral Sciences, Mouse Behavioral and Neuroendocrine Analysis Core Facility, ${ }^{2}$ Department of Cell Biology, and \\ ${ }^{3}$ Departments of Cell Biology and Neurobiology, Duke University Medical Center, Durham, North Carolina 27710
}

The vesicular monoamine transporter 2 (VMAT2) is localized primarily within the CNS and is responsible for transporting monoamines from the cytoplasm into secretory vesicles. Because reserpine (a VMAT inhibitor) can precipitate depressive-like symptoms in humans, we investigated whether Vmat2 heterozygous (HET) mice present with depressive-like behaviors. The mutants showed locomotor and rearing retardation in the open field and appeared anhedonic to 1 and 1.5\% sucrose solutions. Immobility times for Vmat 2 heterozygotes were prolonged in forced swim and imipramine normalized this behavior. HET animals also showed enhanced immobility in tail suspension and this response was alleviated by fluoxetine, reboxetine, and bupropion. Stimulated GTP $\gamma \mathrm{S}$ binding indicated that $\alpha_{2}-$ adrenergic receptors in HET hippocampus were more sensitive to UK 14,304 (5-bromo- $N$-(4,5-dihydro-1- $H$-imidazol-2-yl)-6quinoxalinamine) stimulation than in wild type (WT) mice. In learned helplessness, mice were exposed to a shuttle box for $4 \mathrm{~d}$ or were given inescapable foot-shocks for the same time period. On day 5 , all animals were tested in shock escape. Failure rates and the latency to escape were similar for WT and HET mice that were only pre-exposed to the test apparatus. In foot-shock groups, learned helplessness was more robust in heterozygotes than in WT controls. Basal secretion of serum corticosterone was not distinguished by genotype; however, corticosterone levels in mutants were more responsive to stress. Anxiety-like responses of WT and HET animals in the open field, light-dark exploration, zero maze, and novelty-suppressed feeding tests were indistinguishable. Collectively, these findings suggest that Vmat2 heterozygotes display a depressive-like phenotype that is devoid of anxiety-like behavior.

Key words: vesicular monoamine transporter 2; anxiety; locomotion; anhedonia; depressive-like behavior; antidepressant; stress

\section{Introduction}

The vesicular monoamine transporter (VMAT) is a transmembrane protein responsible for transporting cytoplasmic monoamines into secretory vesicles by an energy-dependent proton gradient (Knoth et al., 1981; Johnson, 1988). Two VMAT genes have been cloned and their proteins are structurally related, but pharmacologically distinct (Erickson et al., 1992; Liu et al., 1992; Peter et al., 1994, 1995). VMAT1 resides in peripheral tissues and developing neurons, whereas VMAT2 is expressed primarily within the CNS (Mahata et al., 1993; Gonzalez et al., 1994; Peter et al., 1995). VMAT2 has been implicated in cellular processes that include monoamine storage (Erickson et al., 1996), protection of transmitter from oxidation and neurotoxins (Liu et al., 1992), and control of quantal secretion of neurotransmitter (Pothos et

\footnotetext{
Received 0ct. 8, 2006; revised Aug. 14, 2007; accepted Aug. 14, 2007.

This work was supported in part by a Postdoctoral Fellowship from the Naito Foundation in Japan (M.F.), a Postdoctoral Fellowship from the American Psychological Association (R.M.R.), a Howard Hughes Neuroscience Forum Undergraduate Fellowship (S.X.J.), a Howard Hughes Precollege Program Fellowship (L.E.P.), unrestricted funds from Merck, Sharp and Dohme (W.C.W.), and National Institute of Mental Health Grant MH60451 (M.G.C.). We thank Dr. Vladimir Pogorelov for showing us how to score the forced swim videos and Liping Du for maintaining the mice.

Correspondence should be addressed to William C. Wetsel, Department of Psychiatry and Behavioral Sciences, Duke University Medical Center, 028 CARL Building, Research Drive, Durham, NC 27710. E-mail: wetse001@mc.duke.edu.

D01:10.1523/JNEUROSCI.4388-06.2007

Copyright $\odot 2007$ Society for Neuroscience $\quad 0270-6474 / 07 / 2710520-10 \$ 15.00 / 0$
}

al., 2000). Several neurological and psychiatric conditions have been ascribed to VMAT2 dysfunction (Miller et al., 1999; Riddle et al., 2002). For instance, the transporter may assist in preventing neuronal damage in Parkinson's disease and 1-methyl-4-phenyl1,2,3,6-tetrahydropyridine-induced parkinsonism (Daniels and Reinhard, 1988; Liu et al., 1992; Miller et al., 1999). Amphetamines perturb VMAT2 function and may contribute to behavioral sensitization and other processes associated with drug abuse (Sulzer and Rayport, 1990; Takahashi et al., 1997; Wang et al., 1997). Importantly, treatment with reserpine, an irreversible inhibitor of the VMAT, leads to depletion of vesicular monoamine stores and it can precipitate depressive-like symptoms in humans (Freis, 1954). This effect has provided a basis for the monoamine hypothesis of depression (Schildkraut, 1965; Maes and Meltzer, 1994). Nevertheless, the contribution of VMAT2 to depressivelike behaviors is obscure.

To more fully understand the physiological role of VMAT2, several investigators have deleted this gene in mice (Takahashi et al., 1997; Wang et al., 1997; Fon et al., 1997). Vmat2 homozygous mutants [knock-outs (KOs)] die soon after birth, whereas heterozygotes survive with normal growth, feeding, and reproductive behaviors. Levels of dopamine (DA), norepinephrine (NE), and serotonin (5-HT) are reduced by $94-99 \%$ in neonatal Vmat2-KO brain and are decreased by 42,23 , and 34\%, respectively, in heterozygous (HET) mice (Fon et al., 1997). Basal ex- 
tracellular levels of DA in striatum are depressed by $\sim 40 \%$ and potassium-stimulated release is reduced fourfold compared with wild type (WT) controls (Wang et al., 1997). The HET mice are more responsive to cocaine and amphetamine in the open field (Wang et al., 1997) and show reduced amphetamine-conditioned place preference than WT animals (Takahashi et al., 1997).

Given the effects of reserpine on depressive-like symptoms in humans (Freis, 1954), we examined whether Vmat2 heterozygotes would display a similar phenotype. Because anxiety may be comorbid with depression (Zimmerman et al., 2002), we determined whether these mutants also presented with these behaviors. Finally, glucocorticoid responses were compared under basal and stressed conditions.

\section{Materials and Methods}

Animals. The Vmat 2 line of 129/C57BL/6 mice was generated by deleting the coding region for transmembranes 3 and 4 from the VMAT2 protein (Wang et al., 1997). WT and Vmat2 HET mice (3-5 months of age) were obtained from C57BL/6J $\times 129 \mathrm{~Sv} / \mathrm{J}$ hybrids that had been backcrossed with C57BL/6J mice for 10 generations. Animals were given food and water ad libitum and were housed three to five animals/cage in a temperature- $\left(22^{\circ} \mathrm{C}\right)$ and humidity-controlled $(45 \%)$ room with a $14: 10$ $\mathrm{h}$ light/dark cycle (lights on at 7:00 A.M.). Except where noted, all experiments were conducted with naive mice and animals were transferred to the experimental rooms at least $2 \mathrm{~h}$ before testing. All investigations occurred during the light phase of the light-dark cycle and were conducted with an approved animal protocol from the Duke University Institutional Animal Care and Use Committee in accordance with $\mathrm{Na}-$ tional Institutes of Health guidelines for the care and use of animals.

Drugs. Imipramine, fluoxetine, bupropion, quinpirole, 5-bromo- $N$ (4,5-dihydro-1- $H$-imidazol-2-yl)-6-quinoxalinamine (UK 14,304), and 8-hydroxy-2-(di- $N$-propylamino)tetralin (8-OH-DPAT) were purchased from Sigma (St. Louis, MO), whereas reboxetine was bought from Tocris Biosciences (Ellisville, MO). The antidepressants were reconstituted in sterile water and given (i.p.) in a $5 \mathrm{ml} / \mathrm{kg}$ volume.

Open field. Mice were placed into an open field $(21 \times 21 \times 30 \mathrm{~cm})$ illuminated at 340 lux, where horizontal (distance traveled in centimeters) and vertical activities (beam breaks) were measured at 5 min intervals over $30 \mathrm{~min}$ as described previously (Pogorelov et al., 2005). The total distance traveled was monitored by eight photobeams, spaced 2.5 $\mathrm{cm}$ apart, positioned $2.25 \mathrm{~cm}$ from the floor, and located around the perimeter of the open field (AccuScan Instruments, Columbus, $\mathrm{OH}$ ). Vertical activity monitors consisted of eight photobeams, spaced $2.5 \mathrm{~cm}$ apart, positioned $8.25 \mathrm{~cm}$ from the floor, and located on opposite walls of the open field. Times spent in the perimeter $(10.5 \times 5.25 \mathrm{~cm})$, corners $(5.25 \times 5.25 \mathrm{~cm})$, and center zone $(10.5 \times 10.5 \mathrm{~cm})$ were measured with the VersaMax program (AccuScan Instruments). Effects of antidepressants on locomotor activity were studied by habituating the mice to the apparatus for $1 \mathrm{~h}$, injecting them with antidepressant, and immediately returning them to the open field for $30 \mathrm{~min}$.

Light-dark exploration test. The apparatus consisted of a mouse shuttle box where the chambers $(20 \times 16 \times 21 \mathrm{~cm} /$ chamber $)$ were separated by an automated sliding door (MedAssociates, St. Albans, VT). One chamber was illuminated with a $170 \mathrm{~mA}$ high-intensity light (with house lights, total illumination was $\sim 600$ lux), whereas the other was enclosed by a black cloth. Mice were placed on the lighted side; $5 \mathrm{~s}$ later the door to the adjoining chamber was opened and mice were given free access to the entire apparatus for $5 \mathrm{~min}$. The latency to first enter the darkened side, time spent on each side, head pokes into each side, and the number of transitions between chambers were determined by MedAssociates software.

Zero maze. Details of the zero maze have been described previously (Shepherd et al., 1994; Pogorelov et al., 2005). The maze was illuminated at 50-60 lux and surrounded by black curtains. A video camera was suspended $100 \mathrm{~cm}$ above the maze. An animal was placed into a closed quadrant and allowed to freely investigate the maze for $5 \mathrm{~min}$. Subsequently, videos were analyzed with the Observer program (Noldus, Ster- ling, VA) and were scored for the latency to enter the open areas, percent time spent in the open areas, total number of transitions between quadrants, as well as stretch-attend postures, head-dips, grooming, rearing, and freezing behavior.

Novelty-suppressed feeding. Before testing, food was removed from the home cage for $\sim 24 \mathrm{~h}$, whereas water was provided ad libitum. At the end of this time, a single $2 \times 2.5 \mathrm{~cm}$ oval food pellet (PMI Nutrition International, Brentwood, $\mathrm{MO}$ ) was placed on a circular piece of white filter paper $(12 \mathrm{~cm}$ diameter) positioned in the center of the open field $(42 \times$ $42 \times 30 \mathrm{~cm})$. Each mouse was removed from its home cage, transferred to a holding cage without food or water for $30 \mathrm{~min}$, and then placed in a corner of the open field under 1400 lux illumination. The latency to first bite the food pellet and consumption over $5 \mathrm{~min}$ was recorded. The mouse was immediately removed to the home cage containing a single food pellet on a piece of white filter paper positioned in the center of the cage. The latency to first bite the food pellet and consumption over $5 \mathrm{~min}$ was recorded.

Anhedonia test. This test was conducted in the home cage where mice were housed individually for $7 \mathrm{~d}$ before and, subsequently, throughout the study. The water bottle was always removed $2.5 \mathrm{~h}$ before the beginning of the dark cycle. Two bottles, both of which contained sterile water, were supplied $1.5 \mathrm{~h}$ after the beginning of dark cycle ( $4 \mathrm{~h}$ fluid deprivation) and mice were allowed to drink for $1 \mathrm{~h}$ over this period. After this time, the bottles were removed and the original water bottle was returned to the home cage. The procedure was performed daily until water consumption was stable. Subsequently, mice were water deprived as described except they were presented with two bottles each containing $0.5 \%$ sucrose solution for $1 \mathrm{~h}$ over 3 consecutive days. After training, a twobottle choice test was conducted over consecutive days where water was paired each day with $0.5 \%$ sucrose, $1 \%$ sucrose, $1.5 \%$ sucrose, $2 \%$ sucrose, or with $0.0075 \mathrm{~mm}, 0.015 \mathrm{~mm}$, or $0.030 \mathrm{~mm}$ quinine for $1 \mathrm{~h}$. At the end of each $1 \mathrm{~h}$ test period, animals were always given their original single bottle of water. The total volume of liquid consumed in the $1 \mathrm{~h}$ test was measured each day by weighing the bottles before and after training/ testing. Preference for the sucrose or quinine solutions was determined by dividing the volume of sucrose or quinine consumed by the total liquid consumption.

Forced swim. Mice in this test were naive or had been tested previously in the zero maze. In forced swim (Porsolt et al., 1977), animals were given vehicle or imipramine (i.p.) and were placed $30 \mathrm{~min}$ later into a beaker ( $15 \mathrm{~cm}$ diameter) of water held at $25^{\circ} \mathrm{C}$ with a depth of $15 \mathrm{~cm}$ (Xu et al., 2000). Behavior was videotaped for $6 \mathrm{~min}$ from the side of the beaker and scored subsequently for struggling behavior. Immobility time refers to the time that the animal spent floating or engaged in minimal activity to keep afloat for at least $3 \mathrm{~s}$, latency to the first episode of immobility was defined as the time required for the mouse to first cease all movement for $>3 \mathrm{~s}$, and the duration of this first immobility bout was recorded in seconds. Subtle movements of feet, tail, or head required to maintain the eyes, ears, and nose above the surface of the water were excluded as immobility. The video tapes were scored by investigators unfamiliar with the genotypes of the mice.

Tail suspension. Animals were naive or had been tested previously in the zero maze. Tail suspension was conducted in a MedAssociates apparatus where the body weight of the mouse was used as a control to determine the magnitude of its struggle activity. The test was run in the afternoon similar to that described previously (Steru et al., 1985). Mice were administered vehicle, fluoxetine, reboxetine, or bupropion (i.p.) and were tested $30 \mathrm{~min}$ later. Immobility times were determined over 6 min using MedAssociates software.

Learned helplessness. The apparatus consisted of a shuttle box where the chambers were separated by an automated sliding door (MedAssociates); the test was similar to that outlined by Shanks and Anisman (1989). Before beginning the experiment, group-housed animals were assigned to two different groups: a no-foot-shock (NFS) and a foot-shock (FS) group. On training days $1-4$, all mice were acclimated to the twochambered apparatus for $5 \mathrm{~min}$. After acclimation, NFS mice were allowed to explore the apparatus for $60 \mathrm{~min}$, whereas FS mice were given the same opportunity to explore, but were administered $3600.15 \mathrm{~mA}$ foot shocks for $2 \mathrm{~s}$ (10 s variable intertrial interval) each day. Mice were 
removed from the apparatus immediately after each session and housed in individual cages throughout the experiment. On day 5, escape testing was performed, where all mice in both groups were given 30 trials (30-90 s intertrial interval) consisting of escapable $0.15 \mathrm{~mA}$ foot shocks (Shanks and Anisman, 1989). Briefly, the door between the chambers was closed during the $5 \mathrm{~min}$ acclimatization period. On the first two test trials, the door opened simultaneously with foot-shock onset. On the latter 28 trials, the door did not open until $2 \mathrm{~s}$ had elapsed after onset of foot shock. The foot shock was terminated when mice escaped to the nonshocked compartment or if they failed to escape within $20 \mathrm{~s}$. The numbers of unsuccessful escapes, chamber crossings, and latencies to escape were determined by MedAssociates software.

Serum corticosterone. For analyses of glucocorticoid levels in blood, naive animals were housed individually for at least $10 \mathrm{~d}$ before the experiment. On the day of the experiment, cages were removed individually from the animal colony on Saturday from 7:30 to 8:30 A.M. or at 6:00 to 7:00 P.M. and mice were quickly killed by decapitation to analyze basal secretion. To measure corticosterone levels under stress, mice were killed immediately after completion of the tail suspension test. Trunk blood was collected, allowed to clot, and red blood cells were separated from serum by centrifugation. Serum was stored at $-80^{\circ} \mathrm{C}$ until time of radioimmunoassay using a kit from ICN Biomedicals (Costa Mesa, CA).

$\left[{ }^{35} S\right] G T P \gamma S$ binding. WT and Vmat2 HET mice were killed by decapitation, the brain was removed, sectioned sagittally at the midline, the area between the superior colliculus and cortex was exposed, and the hippocampus was dissected. Alternatively, the whole striatum was dissected as described previously (Pogorelov et al., 2005). Briefly, for analysis of 5-HT 1A receptor-mediated GTP $\gamma \mathrm{S}$ responses, the hippocampus was dissected, homogenized in ice-cold $50 \mathrm{~mm}$ Tris- $\mathrm{HCl}$ buffer, $\mathrm{pH}$ 7.4, and centrifuged at $40,000 \times g$ for $10 \mathrm{~min}$ at $4^{\circ} \mathrm{C}$ (Alper and Nelson, 1998). The pellet was washed and resuspended in buffer, vortexed vigorously, incubated at $37^{\circ} \mathrm{C}$ for $10 \mathrm{~min}$ in a shaking water bath, and centrifuged again. The pellet was washed, resuspended in buffer, and frozen at $-80^{\circ} \mathrm{C}$. The next day, the homogenate was centrifuged, the pellet was washed with assay buffer (67 mM Tris, 0.267 mM EGTA, $160 \mathrm{~mm} \mathrm{NaCl}, 4$ mм $\mathrm{MgCl}_{2}$, and $0.136 \mathrm{~mm} \mathrm{DTT,} \mathrm{pH} \mathrm{7.4),} \mathrm{and} \mathrm{an} \mathrm{aliquot} \mathrm{was} \mathrm{taken} \mathrm{for}$ protein assay (Bradford, 1976). GTP $\gamma \mathrm{S}$ binding was measured in a total volume of $0.8 \mathrm{ml}$ where nonspecific binding tubes with $100 \mu \mathrm{M}$ GTP (Sigma), basal binding tubes with water, and stimulated binding tubes with $10 \mu \mathrm{M} 8-\mathrm{OH}-\mathrm{DPAT}$ were run in quadruplicate with $50 \mu \mathrm{g}$ protein, 100 pM $\left[{ }^{35}\right.$ S $]$ GTP $\gamma S$ (PerkinElmer Life Sciences, Boston, MA), and 300 $\mu \mathrm{M}$ GDP (Sigma). Tubes were incubated for $20 \mathrm{~min}$ at $37^{\circ} \mathrm{C}$ and samples were filtered with GF/B filters (Brandel, Gaithersburg, MD) using icecold water, and counted in Lefko-Fluor (Research Products International, Mount Prospect, IL).

For $\alpha_{2}$-adrenergic receptor responses, the hippocampus was homogenized in ice-cold buffer containing (in $\mathrm{mm}$ ) 50 Tris- $\mathrm{HCl}, \mathrm{pH} 7.4,1$ EGTA, $3 \mathrm{MgCl}_{2}, 1 \mathrm{DTT}$, and centrifuged at $48,000 \times g$ for $10 \mathrm{~min}$ at $4^{\circ} \mathrm{C}$. The pellet was washed and resuspended in buffer, and centrifuged again. This procedure was repeated. The pellet was washed in buffer containing (in mM) 50 Tris, pH 7.4, $3 \mathrm{MgCl}_{2}, 1$ EGTA, $100 \mathrm{NaCl}$, and 1 DTT, and an aliquot was taken for protein assay (Bradford, 1976). GTP $\gamma S$ binding was measured in a total volume of $0.8 \mathrm{ml}$ where nonspecific binding tubes with $100 \mu \mathrm{M}$ GTP, basal binding tubes with assay buffer, and stimulated binding tubes with $10 \mu \mathrm{M}$ UK 14,304 were run in quadruplicate with 50 $\mu$ g protein, $100 \mathrm{pm}\left[{ }^{35} \mathrm{~S}\right] \mathrm{GTP} \gamma \mathrm{S}$, and $100 \mu \mathrm{M}$ GDP. Tubes were incubated for $60 \mathrm{~min}$ at $30^{\circ} \mathrm{C}$ and samples filtered with GF/B filters using $50 \mathrm{~mm}$ Tris buffer, $\mathrm{pH} 7.4$, and counted as described above.

For DA $\mathrm{D}_{2}$ receptor responses, the striatum was homogenized in buffer containing (in mM) 20 HEPES, $5 \mathrm{MgCl}_{2}, 1$ EDTA, $100 \mathrm{NaCl}$, and 1 DTT, $\mathrm{pH} 7.4$, and centrifuged at $1000 \times \mathrm{g}$ for $10 \mathrm{~min}$ at $4^{\circ} \mathrm{C}(\mathrm{Xu}$ et al., 2000). The supernatant was retrieved, vortexed vigorously, incubated at
B

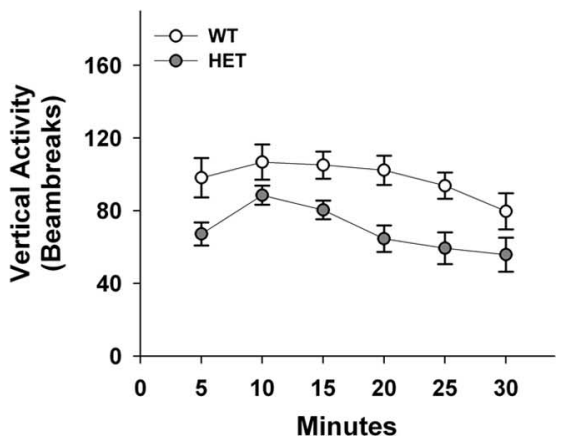

$30^{\circ} \mathrm{C}$ for $10 \mathrm{~min}$ in a shaking water bath, and centrifuged at $20,000 \times g$ for $30 \mathrm{~min}$ at $4^{\circ} \mathrm{C}$. The pellet was washed with buffer, resuspended, and centrifuged again. The procedure was repeated and the final pellet was washed in buffer containing (in mM) 20 HEPES, $5 \mathrm{MgCl}_{2}, 150 \mathrm{NaCl}$, and 0.136 DTT, pH 7.4, with an aliquot was taken for protein assay (Bradford, 1976). Assay tubes were preincubated with GDP for $10 \mathrm{~min}$. GTP $\gamma \mathrm{S}$ binding was measured in a total volume of $0.2 \mathrm{ml}$ where nonspecific binding tubes with $500 \mu \mathrm{M}$ GTP, basal binding tubes with assay buffer, and stimulated binding tubes with $1 \mathrm{~mm}$ quinpirole were run in quadruplicate with $20 \mu \mathrm{g}$ protein, $200 \mathrm{pm}\left[{ }^{35} \mathrm{~S}\right] \mathrm{GTP} \gamma \mathrm{S}$, and $50 \mu \mathrm{M}$ GDP. Tubes were incubated in a $30^{\circ} \mathrm{C}$ water bath for $60 \mathrm{~min}$, filtered with GF/B filters using $10 \mathrm{~mm}$ Tris buffer, $\mathrm{pH} 7.4$, and counted in a scintillation counter as described above.

Basal binding is presented as basal minus nonspecific binding, "stimulated" denotes stimulated minus nonspecific binding, the percent stimulation is represented as stimulated divided by basal binding times 100 , and the stimulated/basal ratio refers to the ratio of stimulated to basal binding.

Statistics. The data are presented as means and SEMs. All analyses were conducted with the Statistical Package for the Social Sciences, version 11.0 (SPSS, Chicago, IL). Univariate ANOVA was used to analyze learned helplessness results, the drug effects in the forced swim and tail suspension tests, and the baseline serum corticosterone levels. Multivariate ANOVA was used for active avoidance. Repeated-measures ANOVA (RMANOVA) were used to evaluate performance in the open field, novelty-suppressed feeding, and anhedonia tests. Bonferroni-corrected pairwise comparisons were used as the post hoc tests. Cumulative horizontal and vertical activities in the open field, time spent in the perimeter, corners, and center of the open field, data from the light-dark exploration test, zero maze, immobility times for vehicle-treated mice in forced swim and tail suspension tests, serum corticosterone for stressed groups, and GTP $\gamma S$ binding were analyzed by independent samples two-tailed $t$ tests. A $p<0.05$ was considered significant.

\section{Results}

\section{Vmat2 heterozygotes display locomotor retardation}

To determine whether Vmat2 heterozygotes display locomotor retardation, we monitored their spontaneous activity in the open field. When horizontal activity was examined, a RMANOVA for within subjects demonstrated significant main effects of time $\left(F_{(5,85)}=8.833 ; p<0.01\right)$ with no significant time by genotype interaction (Fig. 1A). Importantly, the between subjects test showed that WT mice $(1868 \pm 111.4 \mathrm{~cm})$ were more active $\left(F_{(1,17)}=6.075 ; p<0.03\right)$ than HET animals $(1436 \pm 132.8 \mathrm{~cm})$.

In addition to horizontal activity, vertical activity was also examined (Fig. $1 B$ ). The within subjects RMANOVA revealed significant main effects of time $\left(F_{(5,85)}=5.313 ; p<0.01\right)$, but no significant time by genotype interaction. When the data were collapsed over time for each genotype, the between subjects test 
found significant differences $\left(F_{(1,17)}=13.981 ; p<0.01\right)$ between WT $(585 \pm 32.5$ beam breaks) and HET mice ( $415 \pm 31.6$ beam breaks). Collectively, these open field results show that the Vmat2 HET mice have reduced activities, an endophenotype in human depressed patients.

\section{Vmat 2 heterozygotes do not present with anxiety-like behaviors}

Anxiety is frequently comorbid in patients with major depression (Zimmerman et al., 2002). To determine whether Vmat2 mice display anxiety-like responses, we first examined open field behavior. Reduced time spent in the center or increased time in the corners and perimeter of the open field can be taken as indices of anxiety in rodents (Treit and Fundytus, 1988). No genotype differences were discerned with times spent in the perimeter (WT, $1027 \pm 43.2$; HET, $1148 \pm 69.2$ s), corners (WT, $303 \pm 27.2$; HET, $380 \pm 63.3 \mathrm{~s}$ ), or center of the open field (WT, $768 \pm 49.1$; HET, $651 \pm 69.1 \mathrm{~s}$ ) over the $30 \mathrm{~min}$ test period. In the light-dark exploration test, anxious mice tend to avoid brightly lit environments (Crawley and Goodwin, 1980). Again, no genotype differences were observed for the latency to enter the darkened chamber (WT, $8.2 \pm 1.18$; HET, $8.5 \pm 0.81 \mathrm{~s}$ ), numbers of head pokes into the lighted (WT, 28.6 \pm 3.65 ; HET, $21.5 \pm 3.30$ ) or darkened chambers (WT, $11.7 \pm 2.03$; HET, $13.9 \pm 2.46$ ), time spent on the light side (WT, $108.1 \pm 11.73$; HET, $133.4 \pm 10.59 \mathrm{~s}$ ), or number of transitions between the light and dark chambers (WT, $15.9 \pm$ 2.25; HET, $16.6 \pm 1.52$ ). The zero maze relies on the inherent conflict between exploration of a novel area and avoidance of its aversive features (Shepherd et al., 1994). WT and HET mice had similar latencies to leave the closed area and enter the open areas of the maze (WT, $198.9 \pm 23.80$; HET, $211.8 \pm 20.90 \mathrm{~s}$ ), they spent similar percentages of time in the open areas (WT, $4.4 \% \pm 1.18$; HET, $3.8 \% \pm 0.82$ ), and they crossed from the closed to open to closed areas a similar number of times (WT, $0.6 \pm$ 0.20 ; HET, $0.6 \pm 0.19$ ). Additionally, the numbers of stretchattend postures (WT, $22.3 \pm 1.64$; HET, $22.9 \pm 1.94$ ), head dips (WT, $26.9 \pm 2.45$; HET, $24.1 \pm 2.31$ ), and episodes of rearing (WT, $10.4 \pm 1.31$; HET, $9.9 \pm 1.60$ ), grooming (WT, $1.1 \pm 0.14$; HET, $1.5 \pm 0.26$ ), and duration of freezing behaviors (WT, $8.6 \pm$ 1.47; HET, $8.3 \pm 1.60 \mathrm{~s}$ ) were also similar between genotypes. Finally, novelty-suppressed feeding has been used as a test for anxiety-like (Merali et al., 2003) and depressive-like behaviors (Dulawa and Hen, 2005). A within-subjects RMANOVA revealed significant main effects of test environment (i.e., novel open-field vs familiar home cage; $\left.F_{(1,25)}=26.521 ; p<0.01\right)$, but the test environment by genotype interaction was not significant. The between subjects test supported an absence of genotype effects, showing that the latency to feed was similar for WT (novel, $167.4 \pm 24.02 \mathrm{~s}$; familiar, $79.3 \pm 14.21 \mathrm{~s}$ ) and HET mice (novel, $167.4 \pm 17.96 \mathrm{~s}$; familiar, $91.2 \pm 11.29 \mathrm{~s})$ in each context. Bonferroni-corrected pairwise comparisons determined that both WT and HET mice engaged their food pellets more quickly in the familiar than novel environment $(p$ values $<0.01$ ). When permitted to consume the food pellet over $5 \mathrm{~min}$ in either environment, both WT controls (novel, $0.13 \pm 0.015 \mathrm{~g}$; familiar, $0.15 \pm 0.006 \mathrm{~g}$ ) and Vmat2 heterozygotes (novel, $0.11 \pm 0.016 \mathrm{~g}$; familiar, $0.15 \pm 0.019 \mathrm{~g}$ ) ate similar amounts of food. Collectively, these experiments indicate that the Vmat2 HET mice do not present with an anxiety-like phenotype.

\section{Vmat2 heterozygotes appear anhedonic}

Diminished interest or pleasure is one of the core symptoms of major depression (American Psychiatric Association, 1994). To
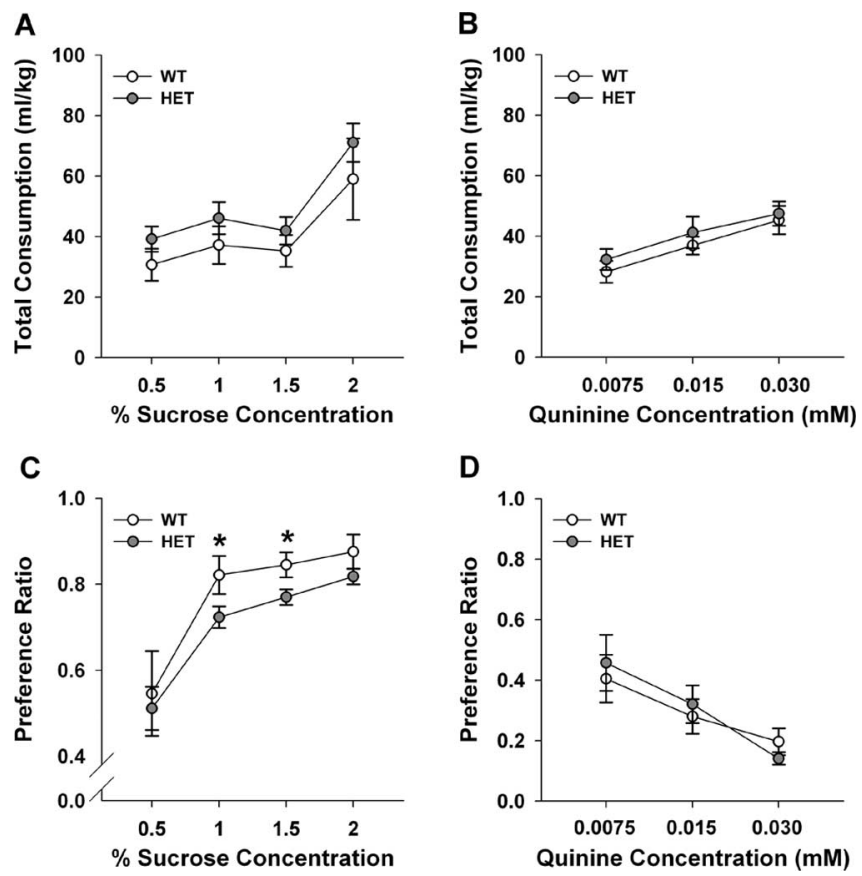

Figure 2. Responses of WT and Vmat2 HET mice in an anhedonia test. $\boldsymbol{A}$, Total fluid consumption of water and sucrose solutions across testing. $\boldsymbol{B}$, Total fluid consumption of water and quinine solutions across testing. $\boldsymbol{C}$, Preferences for sucrose solutions over that for water. $\boldsymbol{D}$ Preferences for quinine solutions over that for water. Preference was determined by dividing the volume of sucrose or quinine consumed by the total liquid consumption. ${ }^{*} p<0.05$ compared with WT mice; $n=7-10$ mice/genotype.

determine whether Vmat2 mice were anhedonic, WT and HET animals were deprived of liquids for $4 \mathrm{~h}$ daily and fluid consumption was monitored subsequently over $1 \mathrm{~h}$ using a two-bottle test during the dark phase of the light-dark cycle. Body weights and food intakes were not different between the genotypes across days (data not shown). When mice were given a choice between water and $0.5,1,1.5$, or $2 \%$ sucrose, total overall fluid intake was similar between WT and HET mice (Fig. 2A). Additionally, total fluid intake was similar for WT and HET animals exposed to water and $0.0075,0.015$, or $0.030 \mathrm{~mm}$ quinine (Fig. $2 B$ ) However, both genotypes were differentially responsive to the various concentrations of sucrose or quinine. RMANOVA for concentration was significant for the sucrose-water $\left(F_{(3,42)}=27.528 ; p<0.01\right)$ and for the quinine-water experiments $\left(F_{(2,28)}=19.837 ; p<0.01\right)$. For the sucrose-water pairings, Bonferroni-corrected pairwise comparisons showed overall fluid intake with the $2 \%$ sucrosewater pairing was higher than for other pairings (Fig. $2 \mathrm{~A}$ ). With respect to the quinine-water comparisons (Fig. $2 B$ ), total fluid consumption was increased from 0.0075 to $0.015 \mathrm{~mm}$ quinine $(p<0.01)$ and from 0.0075 to the $0.030 \mathrm{~mm}$ quinine $(p<0.01)$; enhanced fluid intake from 0.015 to the $0.030 \mathrm{~mm}$ quinine-water pairing approached significance $(p<0.06)$.

Distinct preferences emerged from the sucrose-water pairings. RMANOVA demonstrated a significant main effect of sucrose concentration $\left(F_{(3,42)}=14.565 ; p=0.01\right)$ and a significant concentration by genotype interaction $\left(F_{(3,42)}=2.794 ; p<0.05\right)$. Preference for $0.5 \%$ sucrose (51-54\% preference) was not different from that for water for both genotypes (Fig. 2C). However, WT mice showed higher preferences for $1,1.5$, and $2 \%$ than $0.5 \%$ sucrose; preferences between 1 and 2\% sucrose solutions appeared at asymptote and did not differ from each other. In contrast, sucrose intake continued to increase for HET animals and 
Bonferroni comparisons showed that the mutants consumed less of the $1 \%(p<$ $0.03)$ and $1.5 \%$ sucrose solutions $(p<$ $0.01)$ than WT controls. When preference for quinine was evaluated, RMANOVA revealed a significant effect of concentration $\left(F_{(2,28)}=12.726 ; p<0.01\right)$; no significant concentration by genotype interaction emerged (Fig. 2D). Bonferroni tests demonstrated that preference for $0.030 \mathrm{~mm}$ quinine was less than that for the 0.0075 $(p<0.01)$ and $0.015 \mathrm{~mm}$ solutions $(p<$ $0.02)$, which were not different from each other. The quinine results show aversion for this agent is similar for both genotypes. However, the shift in the concentrationresponse curve for sucrose suggests the Vmat2 HET mice may be anhedonic, a key endophenotype in depressed patients.

\section{Immobility in forced swim and tail suspension is alleviated by antidepressants in Vmat 2 HET mice} Forced swim is an acute test where increased immobility time is used as an index of depressive-like behavior in rodents (Porsolt et al., 1977). We observed the HET mice $(281 \pm 14.9 \mathrm{~s})$ to display significant increases in immobility times $\left(t_{(1,16)}\right.$ $=2.471 ; p<0.02)$ compared with their WT vehicle controls $(221 \pm 12.7 \mathrm{~s})$ over the $6 \mathrm{~min}$ test. Acute effects of imipramine, a tricyclic antidepressant that binds the NE and 5-HT transporters, were examined next. Significant genotype $\left(F_{(1,51)}=\right.$ 4.606; $p<0.03)$ and dose effects were detected $\left(F_{(2,51)}=14.130\right.$; $p=0.01$ ); however, no significant interaction emerged (Fig. $3 A$ ). Examination of effects within genotype by Bonferroni tests revealed that immobility times in HET animals were significantly decreased with 5 and $10 \mathrm{mg} / \mathrm{kg}$ imipramine ( $p$ values $<0.01$ ). Similarly, immobility times for WT animals were decreased by the $10 \mathrm{mg} / \mathrm{kg}$ dose $(p<0.04)$.

In addition to examining total immobility time, the latency to first episode of immobility and the duration of immobility for this first bout were analyzed. For the former (Fig. 3B), ANOVA found significant main effects of genotype $\left(F_{(1,44)}=6.436\right.$; $p<$ $0.02)$ and dose $\left(F_{(2,44)}=24.463 ; p<0.01\right)$, but no significant interaction emerged $\left(F_{(2,44)}=2.625 ; p<0.08\right)$. Bonferroni comparisons showed that for vehicle-treated mice, WT animals took longer to reach their first immobility bout than HET animals $(p<0.05)$. However, imipramine, regardless of dose, prolonged this latency for both genotypes relative to the vehicle controls $(p<0.01)$. No genotype differences $(p>0.15)$ were discerned in the latencies to immobility for 5 or $10 \mathrm{mg} / \mathrm{kg}$ imipramine. For the duration of the first bout of immobility (Fig. 3C), ANOVA detected main effects of genotype $\left(F_{(1,44)}=17.957 ; p<0.01\right)$ and dose $\left(F_{(2,44)}=4.067 ; p<0.02\right)$, and the genotype by dose interaction was significant $\left(F_{(2,44)}=5.097 ; p<0.01\right)$. Bonferronicorrected pairwise comparisons demonstrated that for vehicletreated mice, HET animals spent more time in immobility during the first immobility bout than WT littermates $(p<0.01)$. Imipramine treatment did not alter this duration for WT animals relative to the vehicle controls $(p>0.98)$. However, for HET mice the 5 or $10 \mathrm{mg} / \mathrm{kg}$ imipramine doses significantly reduced
B

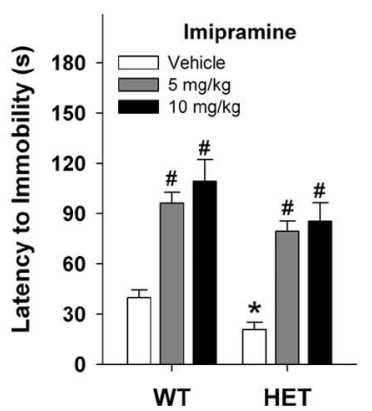

C

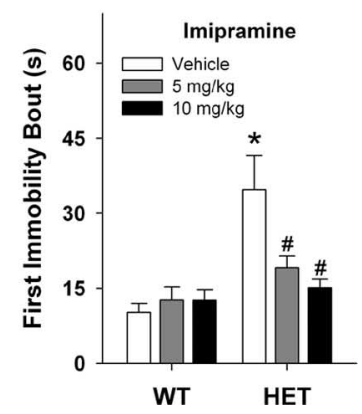

Figure 3. Responses of WT and Vmat2 HET mice in the forced-swim test. $A$, Effects of imipramine on immobility in forced swim of WT and HET mice. $\boldsymbol{B}$, Imipramine effects on the latency to the first episode of immobility. $\boldsymbol{C}$, Duration of first immobility bout

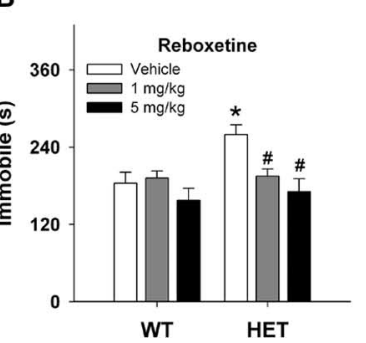

C

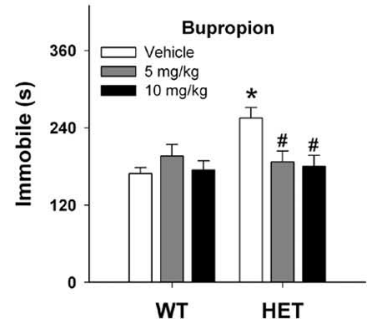

type. 
ical antidepressant (Fig. 4C). Univariate ANOVA found the main effect of dose $\left(F_{(2,62)}=3.2 ; p<0.05\right)$ and the genotype by dose interaction to be significant $\left(F_{(2,62)}=3.131 ; p<0.05\right)$. For HET mice, $5(p<0.01)$ and $10 \mathrm{mg} / \mathrm{kg}$ bupropion $(p<0.01)$ reduced immobility times in a dose-dependent manner to levels that were indistinguishable from the WT littermates. By comparison, no drug effects were discerned in WT mice. Collectively, these data show that fluoxetine, reboxetine, and bupropion attenuate depressive-like behaviors in Vmat2 HET mice.

One reason the vehicle-treated HET mice have increased immobility times in the forced swim and tail suspension tests may be because they are less active. Because the mutants have an overall reduction of activity in the open field, one may anticipate that the optimal doses of fluoxetine, reboxetine, and bupropion that increased their struggling behaviors in tail suspension may enhance also their locomotion in the open field. Although locomotor activity was reduced for Vmat2 heterozygotes during the first 30 $\mathrm{min}$ in the open field, activities were similar over the next $30 \mathrm{~min}$ before drug administration (data not shown). Hence, animals were placed in the open field for $1 \mathrm{~h}$, given vehicle or antidepressant, and immediately returned to the open field for $30 \mathrm{~min}$. A univariate ANOVA for locomotor activity over the $30 \mathrm{~min}$ period after antidepressant administration revealed a significant main effect of treatment $\left(F_{(1,61)}=26.090 ; p<0.01\right)$; effects of genotype or the treatment by genotype interaction were not significant. Bonferroni-corrected pairwise comparisons confirmed that 30 $\mathrm{mg} / \mathrm{kg}$ fluoxetine and $5 \mathrm{mg} / \mathrm{kg}$ reboxetine suppressed locomotion of both WT (fluoxetine, $153 \pm 10.7 \mathrm{~cm}$; reboxetine, $300 \pm 31.5$ $\mathrm{cm}$ ) and HET animals (fluoxetine, $167 \pm 25.8 \mathrm{~cm}$; reboxetine, $263 \pm 42.5 \mathrm{~cm}$ ) relative to their respective vehicle controls (WT, $572 \pm 171.9 \mathrm{~cm}$; HET, $582 \pm 178.4 \mathrm{~cm} ; p<0.04$ ), whereas 10 $\mathrm{mg} / \mathrm{kg}$ bupropion augmented activity of both genotypes (WT, $1121 \pm 191.8 \mathrm{~cm}$; HET, $1302 \pm 293.4 \mathrm{~cm})(p<0.01)$. Bupropion treatment also enhanced locomotor activity relative to that of the fluoxetine- and reboxetine-treated animals $(p<0.01)$. These results show that locomotion is differentially affected by antidepressant treatment and activities in the open field and tail suspension test are not coincident.

\section{GTP $\gamma \mathrm{S}$ binding is enhanced by $\boldsymbol{\alpha}_{2}$-adrenergic receptor stimulation}

The HET mice were more responsive to fluoxetine, reboxetine, and bupropion in tail suspension than WT controls. Because these antidepressants should influence neurotransmission at least in the respective serotonergic, noradrenergic, and dopaminergic systems, we evaluated responses in each of these systems by GTP $\gamma \mathrm{S}$ binding. Hippocampal basal responses were significantly higher $\left(t_{(1,15)}=2.466 ; p<0.03\right)$ in WT than HET mice (Table 1$)$. When samples were stimulated with $10 \mu \mathrm{M} 8$-OH-DPAT, responses were higher $\left(t_{(1,15)}=2.247 ; p<0.04\right)$ in WT than HET hippocampus. Additional analyses of the stimulation response failed to reveal any genotype differences. Hence, overall basal binding, as well as stimulated GTP $\gamma \mathrm{S}$ binding to the 5-HT 1A receptor agonist is higher in hippocampus for WT than Vmat2 HET mice. However, when the percent stimulated response or ratio of stimulated to basal binding is evaluated, no genotype differences are evident.

GTP $\gamma \mathrm{S}$ responses were assessed also in hippocampus under basal conditions and in response to $\alpha_{2}$-adrenergic stimulation with $10 \mu \mathrm{M}$ UK 14,304. Basal activation was significantly higher $\left(t_{(1,10)}=3.861 ; p<0.01\right)$ in WT than in HET hippocampus (Table 1$)$. Similarly, stimulated activity was also higher $\left(t_{(1,10)}=\right.$ $2.491 ; p<0.03)$ in WT than HET mice. Despite these changes,
Table 1. Parameters for GTP- $\gamma$ S binding in WT and Vmat2 HET mice

\begin{tabular}{lcc}
\hline Binding & WT & HET \\
\hline 5-HT 1A receptor & $728 \pm 55.7$ & \\
Basal (dpm) & $1205 \pm 73.4$ & $572 \pm 35.7^{*}$ \\
Stimulated (dpm) & $68 \pm 10.4$ & $75 \pm 6.1$ \\
Percent stimulation & $1.68 \pm 0.10$ & $1.76 \pm 0.06$ \\
Stimulated/basal & & \\
$\alpha$-Adrenergic receptor & $2259 \pm 92.1$ & $1784 \pm 81.5^{*}$ \\
Basal (dpm) & $2836 \pm 139.3$ & $2380 \pm 119.2^{*}$ \\
Stimulated (dpm) & $25 \pm 1.4$ & $33 \pm 2.0^{*}$ \\
Percent stimulation & $1.25 \pm 0.01$ & $1.33 \pm 0.02^{*}$ \\
Stimulated/basal & & \\
D2 receptor & $3186 \pm 153.1$ & $2929 \pm 144.2$ \\
Basal (dpm) & $3743 \pm 213.1$ & $3592 \pm 151.5$ \\
Stimulated (dpm) & $20 \pm 2.6$ & $23 \pm 2.5$ \\
Percent stimulation & $1.17 \pm 0.04$ & $1.23 \pm 0.02$ \\
Stimulated/basal & & \\
\hline
\end{tabular}

The data are presented as means and SEMs. Basal, Basal minus nonspecific binding; Stimulated, stimulated minus nonspecific binding, Percent stimulation, stimulated divided by basal times 100; Stimulated/basal, the ratio of stimulated to basal. ${ }^{*} p<0.05$ from the WT control. $n=7$ WT and 10 HET hippocampi for the 5 -HT 1A receptor, $n=$ 6 WT and 6 HET hippocampi for the $\alpha_{2}$-adrenergic receptor, and $n=7$ WT and 9 HET striata for the $\mathrm{D}_{2}$ receptormediated GTP- $\gamma$ S binding.

the percent stimulation $\left(t_{(1,10)}=3.272 ; p<0.008\right)$ and the ratio of stimulated to basal activity was significantly higher $\left(t_{(1,10)}=\right.$ 3.321; $p<0.01)$ in hippocampus from HET animals than from WT controls. These findings show that whereas overall basal and stimulated hippocampal GTP $\gamma \mathrm{S}$ binding is increased in WT mice, the magnitude of stimulated $\alpha_{2}$-adrenergic receptormediated GTP $\gamma S$ binding is higher in Vmat2 HET mice.

Because HET animals were more responsive to bupropion in tail suspension than WT controls, GTP $\gamma \mathrm{S}$ binding was analyzed in striatum with $1 \mathrm{~mm}$ quinpirole. Basal and quinpirolestimulated activities were not distinguished by genotype (Table 1). Additionally, the percent stimulation or ratio of stimulated to basal activity was also similar for WT and HET mice. Hence, GTP $\gamma \mathrm{S}$ binding for $\mathrm{D}_{2}$ receptors in striatum is not distinguished by genotype.

\section{Vmat2 heterozygotes are impaired in learned helplessness}

Because the forced-swim and tail-suspension paradigms are acute tests of depressive-like behaviors (Porsolt et al., 1977; Steru et al., 1985), we analyzed responses in a chronic test: learned helplessness (Shanks and Anisman, 1989; Maier and Watkins, 2005). Before beginning the experiment, we tested the sensitivity of WT and HET mice to foot shock (Grove et al., 2004) and found no genotype differences at the level used for learned helplessness. A univariate ANOVA for failure rates revealed significant main effects of genotype $\left(F_{(1,36)}=8.809 ; p<0.01\right)$ and conditioning $\left(F_{(1,36)}=209.276 ; p=0.01\right)$, and a significant genotype by conditioning interaction $\left(F_{(1,36)}=10.084 ; p<0.01\right)$. Bonferroni corrected pairwise comparisons found that both WT and HET mice in the FS group had more failures $(p<0.01)$ than NFS animals; failure rates for the HET animals in the FS group were higher $(p<0.01)$ than the WT controls (Fig. 5A). ANOVA of chamber crossings observed the main effects of conditioning $\left(F_{(1,36)}=57.835 ; p<0.01\right)$ and the genotype by conditioning interaction to be significant $\left(F_{(1,36)}=5.275 ; p<0.03\right)$. Bonferroni tests noted that both NFS groups had high numbers of chamber crossings and were not distinguished by genotype; the FS HET mice had fewer crossings $(p<0.006)$ than the WT animals (Fig. $5 B$ ). Similar results were obtained when behavior was analyzed as the latency to escape (Fig. $5 C$ ). Here, a univariate ANOVA demonstrated significant main effects of genotype 
$\left(F_{(1,36)}=4.38 ; p<0.04\right)$ and conditioning $\left(F_{(1,36)}=204.482 ; p=0.01\right)$, and a significant genotype by conditioning interaction $\left(F_{(1,36)}=4.808 ; p<0.03\right)$. A posteriori tests showed that although no differences for WT and HET NFS groups were evident, the FS groups took longer to the escape foot shock ( $p=0.01)$. Again, Vmat2 heterozygotes in the FS group took longer to escape $(p<0.01)$ than similarly conditioned WT animals. These data demonstrate that HET mice in the FS group are more impaired in learned helplessness than comparable WT controls. Hence, learned helpless is more profound in the Vmat2 heterozygous mutants.

\section{Secretion of corticosterone is elevated in stressed Vmat2 heterozygotes}

The hypothalamic-pituitary-adrenal axis is often activated during depression (Schatzberg et al., 2002). To determine whether corticosterone secretion was abnormal in Vmat 2 mice, animals were evaluated under basal and stressful conditions (Chen et al., 2006). No genotype differences were observed in basal serum corticosterone levels at times of nadir (WT, $19 \pm 5.1$; HET, $21 \pm$ $5.7 \mathrm{ng} / \mathrm{ml}$ ) and peak secretion (WT, $41 \pm 8.3$; HET, $35 \pm 7.1$ $\mathrm{ng} / \mathrm{ml}$ ). By comparison, heterozygous mutants (890 $\pm 66.8 \mathrm{ng} /$ $\mathrm{ml}$ ) showed a more pronounced response to stress of tail suspension $\left(t_{(1,14)}=3.275 ; p<0.01\right)$ than WT controls $(626 \pm 45.0$ $\mathrm{ng} / \mathrm{ml})$. At least under these conditions, Vmat2 heterozygotes are very responsive to stressful stimuli.

\section{Discussion}

Anxiety is often comorbid with depression (Zimmerman et al., 2002). In rodents, some animal models of "depression" display anxiety-like responses (Bale et al., 2000; Schramm et al., 2001; Ansorge et al., 2004; Heim et al., 2004; Wei et al., 2004), whereas others do not (Overstreet, 1993). To determine whether Vmat2 mice show anxiety-like behaviors, animals were subjected to the open field, zero maze, light-dark exploration, and noveltysuppressed feeding tests. Because behaviors of WT and Vmat2 heterozygotes were indistinguishable among these tests, these findings suggest anxiety is not a comorbid feature of the VMAT2 phenotype. Interestingly, these results are similar to those for reserpine-treated hypertensive patients, where anxiety does not appear to accompany their depressive-like states (Freis, 1954).

A core symptom of depression is anhedonia (American Psychiatric Association, 1994). This behavior is modeled as an endophenotype in Flinders rats, learned helpless mice, the chronic mild stress and maternal separation models of depression, and in brain-derived neurotrophic factor (BDNF) conditional KO mice (Overstreet, 1993; El Yacoubi et al., 2003; Heim et al., 2004; Monteggia et al., 2006). In our experiments, food and fluid intake and taste sensitivity to bitter liquids were similar between the genotypes. Analyses of sucrose intake, however, revealed heterozygous animals were less responsive to $1 \%$ and $1.5 \%$ sucrose than WT controls. Because conditioned place preference to amphetamine is less robust also in HET than WT animals (Takahashi et al., 1997), these data suggest the Vmat2 HET mice are anhedonic.

A feature of major depressive disorder is psychomotor retardation or agitation (American Psychiatric Association, 1994). Alterations in spontaneous activity are reported in various animal models of depression. For instance, locomotion is enhanced by
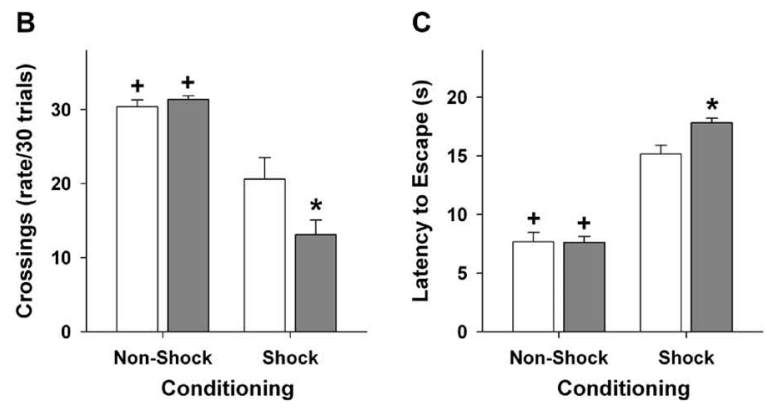

Figure 5. Performance of WT and Vmat2 HET mice in learned helplessness. $\boldsymbol{A}$, Failure rates of mice over the 30 trials of active escape testing. $\boldsymbol{B}$, The numbers of chamber crossings over the 30 test trials. $\boldsymbol{C}$, The latencies to escape over the 30 trials of active cape testing. ${ }^{*} p<0.05$ from the WT foot-shock group; ${ }^{+} p<0.05$ within genotype compared with the respective foot-shocked 政

olfactory bulbectomy and in BDNF conditional KO mice (Kelly et al., 1997; Monteggia et al., 2006), whereas it is reduced in the chronic mild stress, learned helplessness, and swim low-active models, as well as in Flinders rats and 5-HT transporter KO mice (Wagner et al., 1977; Overstreet, 1993; D’Aquila et al., 1994; Weiss et al., 1998; Ansorge et al., 2004). In our experiments, spontaneous locomotion and rearing were decreased in heterozygotes compared with WT controls. It is noteworthy that reserpine, a VMAT inhibitor, can also reduce motor activity (Fischer and Heller, 1967).

Some of the most common tests for depressive-like behaviors in rodents are the forced-swim and tail-suspension assays (Porsolt et al., 1977; Steru et al., 1985). In both tests, HET mice had longer immobility times than WT controls. In forced swim, imipramine reduced immobility times of the heterozygous animals. Similarly, in tail suspension, immobility in HET mice was normalized with fluoxetine, reboxetine, and bupropion in dosedependent manners, whereas WT animals showed little, if any, response to these drugs. Parenthetically, an absence of response for WT animals was anticipated as mice on a C57BL/6J genetic background are relatively unresponsive to imipramine (Liu and Gershenfeld, 2001) and fluoxetine (Lucki et al., 2001). With respect to HET animals, it should be emphasized that their enhanced immobility times are not caused by a decrease in activity because fluoxetine and reboxetine enhance struggle activity in tail suspension, but depress locomotion in the open field. Additionally, bupropion reduces immobility time but increases locomotion. Hence, effects of antidepressants in tail suspension appear behaviorally specific.

Vmat2 HET mice are more sensitive to fluoxetine, reboxetine, and bupropion in tail suspension than WT controls. Because levels of various 5-HT, NE, and DA receptors are similar in WT and HET brain (Takahashi et al., 1997), the differential responsiveness to antidepressants may be caused by alterations in receptor activity. Basal GTP $\gamma \mathrm{S}$ binding in hippocampus was increased in WT mice, whereas no genotype differences in striatum were discerned. These findings suggest that baseline activities for some receptor systems in certain brain areas may be more sensitive to Vmat2 deletion than others. Analyses of stimulated activities showed that $\alpha_{2}$-adrenergic receptors in HET hippocampus were more responsive to UK 14,304 than those from WT mice. This enhanced responsivity may underlie the increased effectiveness of reboxetine and imipramine in the respective tail-suspension and forced-swim tests for HET mice. In contrast, GTP $\gamma \mathrm{S}$ binding for 8-OH-DPAT and quinpirole stimulation may not fully reflect the fluoxetine and bupropion effects in tail suspension. Fluox- 
etine is an indirect agonist that should lead to activation of all 5-HT receptors. Because only 5-HT 1A receptors were examined in hippocampus, the antidepressant actions of fluoxetine could be mediated by other 5-HT receptors in this and/or additional brain regions. With respect to bupropion, the mechanism of action of this drug is complex with effects on dopaminergic, noradrenergic, and cholinergic function (Dwoskin et al., 2006). Hence, stimulated GTP $\gamma \mathrm{S}$ binding with selective receptor agonists in our experiments may not fully simulate the effects of fluoxetine and bupropion on behavior.

In addition to tail suspension, another test of depressive-like behavior is learned helplessness (Shanks and Anisman, 1989). This test mimics many of the features that are thought to accompany depression in humans (Maier and Watkins, 2005). Rodents such as the 5-HT transporter $\mathrm{KO}$ and the glucocorticoid receptor heterozygous mice are deficient in learned helplessness (Lira et al., 2003; Ridder et al., 2005). In our experiment with Vmat2 mice, performance of NFS WT and HET animals is similar. By comparison, repeated foot shocks in both genotypes are sufficient to prolong the latency to escape, enhance the numbers of escape failures, and reduce the numbers of crossings relative to the NFS controls. Under the FS condition, responses of HET animals are more aberrant than those of WT controls. This difference is probably not attributable to a learning impairment because performance of NFS WT and HET mice is identical and because no genotype differences are detected in passive avoidance (Takahashi et al., 1997). Furthermore, this genotype difference for the FS condition may not be attributed to locomotor retardation as the latency to escape and the numbers of escape failures for WT and HET animals are not different under NFS training. Collectively, these data indicate that Vmat2 HET mice are more sensitive to learned helplessness than WT controls.

In HET mice, brain levels of VMAT2 mRNA and protein, and tetrabenazine binding are reduced by at least twofold (Fon et al., 1997; Takahashi et al., 1997; Wang et al., 1997). It is intriguing that VMAT2 mRNA and tetrabenazine binding are decreased also in limbic areas of the Flinders rat (Schwartz et al., 2003) and this animal shows many of the same endophenotypes as the Vmat2 HET mice. Previous investigations have shown that VMAT2 expression and/or its subcellular distributions are modulated by estrogen, stress, monoamine oxidase inhibitors, lithium, psychostimulants, and bupropion (Rehavi et al., 1998; Rusnák et al., 2001; Zucker et al., 2001, 2005; Riddle et al., 2002; Rau et al., 2005). In contrast, chronic reserpine or paroxetine treatments exert no effects on VMAT2 expression, at least in brain regions that contain 5-HT neurons (Vilpoux et al., 2000). In humans, VMAT2 levels are increased in platelets of depressed patients (Zucker et al., 2002) as well as in the thalamus and ventral brainstem of bipolar patients (Zubieta et al., 2000). These results suggest that VMAT2 concentrations may be subject to regulation and, because of its essential role in intracellular transport of monoamines into secretory vesicles, VMAT2 can exert discrete control over secretion of DA, NE, and 5-HT at the synapse (Pothos et al., 2000).

Previous experiments have identified $>223$ single-nucleotide polymorphisms in the human VMAT2 gene SLC18A2 (www. ncbi.nlm.nih.gov/projects/SNP) (Surratt et al., 1993; Glatt et al., 2001, 2006; Iwasa et al., 2001; Kunugi et al., 2001; Burman et al., 2004; Lin et al., 2005). To date, SLC18A2 polymorphisms have been examined only within the context of Parkinson's disease (Burman et al., 2004; Glatt et al., 2006), schizophrenia (Kunugi et al., 2001), long QT syndrome (Iwasa et al., 2001), and alcoholism (Lin et al., 2005). Previously, a qualitative trait locus investigation in mice has identified a site encompassing the Vmat2 gene that is related to citalopram responsiveness in tail suspension (Crowley et al., 2006). Given the effects of reserpine on induction of depressive-like states in humans (Freis, 1954), implications from results of the previous qualitative trait locus experiment, and our present findings with the Vmat2 mice, it will be important to determine in the future whether any of the patients with SLC18A2 polymorphisms were depressed.

We have shown that Vmat2 HET mice display many of features of depressive-like illness that include anhedonia, locomotor retardation, and sensitivity to stress. Because Vmat2 mice do not present with anxiety-like behaviors, depressive-like responses in these animals can be studied without this confound. Because monoamines are reduced in brains of Vmat 2 HET mice, it may be possible to determine the individual and collective contributions of DA, NE, and 5-HT to each of their endophenotypes. In this way, it may be possible to identify novel drug targets and to devise new strategies for treatment of depression in humans.

\section{References}

Alper RH, Nelson DL (1998) Characterization of serotonin 1A receptormediated $\left[{ }^{35} \mathrm{~S}\right] \mathrm{GTP} \gamma \mathrm{S}$ binding in rat hippocampal membranes. Eur J Pharmacol 343:303-312.

American Psychiatric Association (1994) Diagnostic and statistical manual for mental disorders, Ed 4, pp 1-886. Washington, DC: American Psychiatric Association:

Ansorge MS, Zhou M, Lira A, Hen R, Gingrich JA (2004) Early-life blockade of the 5-HT transporter alters emotional behavior in adult mice. Science 306:879-881.

Bale TL, Contarino A, Smith GW, Chan R, Gold LH, Sawchenko PE, Koob GF, Vale WW, Lee KF (2000) Mice deficient for corticotrophinreleasing hormone receptor-2 display anxiety-like behaviour and are hypersensitive to stress. Nat Genet 24:410-414.

Bradford M (1976) A rapid and sensitive method for the quantitation of microgram quantities of protein utilizing the principle of protein-dye binding. Anal Biochem 72:248-254.

Burman J, Tran CH, Glatt C, Freimer NB, Edwards RH (2004) The effect of rare human sequence variants on the function of vesicular monoamine transporter 2. Pharmacogenetics 14:587-594.

Chen A, Zorrilla E, Smith S, Rousso D, Levy C, Vaughan J, Donaldson C, Roberts A, Lee KF, Vale W (2006) Urocortin 2-deficient mice exhibit gender-specific alterations in circadian hypothalamus-pituitary-adrenal axis and depressive-like behavior. J Neurosci 26:5500-5510.

Crawley JN, Goodwin FK (1980) Preliminary report of a simple animal behavior model for the anxiolytic effects of benzodiazepines. Pharmacol Biochem Behav 12:167-170.

Crowley JJ, Brodkin ES, Blendy JA, Berrettini WH, Lucki I (2006) Pharmacogenomic evaluation of the antidepressant citalopram in the mouse tail suspension test. Neuropsychopharmacology 31:2433-2442.

Daniels AJ, Reinhard Jr JF (1988) Energy-driven uptake of the neurotoxin 1-methyl-4-phenylpyridinium into chromaffin granules via the catecholamine transporter. J Biol Chem 263:5034-5036.

D’Aquila PS, Brain P, Willner P (1994) Effects of chronic mild stress on performance in behavioral tests relevant to anxiety and depression. Physiol Behav 56:861-867.

Dulawa SC, Hen R (2005) Recent advances in animal models of chronic antidepressant effects: the novelty-induced hypophagia test. Neurosci Biobehav Rev 29:771-783.

Dwoskin LP, Rauhut AS, King-Pospisil KA, Bardo MT (2006) Rev of the pharmacology and clinical profile of bupropion, an antidepressant and tobacco use cessation agent. CNS Drug Rev 12:178-207.

El Yacoubi M, Bouali S, Popa D, Naudon L, Leroux-Nicollet I, Hamon M, Costentin J, Adrien J, Vaugeois JM (2003) Behavioral, neurochemical, and electrophysiological characterization of a genetic mouse model of depression. Proc Natl Acad Sci USA 100:6227-6232.

Erickson JD, Eiden LE, Hoffman BJ (1992) Expression cloning of a reserpine-sensitive vesicular monoamine transporter. Proc Natl Acad Sci USA 89:10993-10997.

Erickson JD, Schafer MK, Bonner TI, Eiden LE, Weihe E (1996) Distinct pharmacological properties and distribution in neurons and endocrine 
cells of two isoforms of the human vesicular monoamine transporter. Proc Natl Acad Sci USA 93:5166-5171.

Fischer E, Heller B (1967) Pharmacology of the mechanism of certain effects of reserpine in the rat. Nature 216:1221-1222.

Fon EA, Pothos EN, Sun BC, Killeen N, Sulzer D, Edwards RH (1997) Vesicular transport regulates monoamine storage and release but is not essential for amphetamine action. Neuron 19:1271-1283.

Freis ED (1954) Mental depression in hypertensive patients treated for long periods with large doses of reserpine. N Engl J Med 251:1006-1008.

Glatt C, Almonte M, Taylor T, Edwards RH, Freimer N, Tanner C (2006) Structural variants in the vesicular monoamine transporter do not contribute to sporatic Parkinson's disease. Mov Disord 21:426-427.

Glatt CE, DeYoung JA, Delgado S, Service SK, Giacomini KM, Edwards RH, Risch N, Freimer NB (2001) Screening a large reference sample to identify very low frequency sequence variants: comparisons between two genes. Nat Genet 27:435-438.

Gonzalez AM, Walther D, Pazos A, Uhl GR (1994) Synaptic vesicular monoamine transporter expression: distribution and pharmacologic profile. Mol Brain Res 22:219-226.

Grove M, Demyanenko G, Echarri A, Zipfel PA, Quiroz ME, Rodriguiz RM, Playford M, Martensen SA, Robinson MR, Wetsel WC, Maness PF, Pendergast AM (2004) Abi2-deficient mice exhibit defective cell migration, aberrant dendritic spine morphogenesis and deficits in learning and memory. Mol Cell Biol 24:10905-10922.

Heim C, Plotsky PM, Nemeroff CB (2004) Importance of studying the contributions of early adverse experience to neurobiological findings in depression. Neuropsychopharmacology 29:641-648.

Iwasa H, Kurabayashi M, Nagai R, Nakamura Y, Tanaka T (2001) Multiple single-nucleotide polymorphisms (SNPs) in the Japanese population in six candidate genes for long QT syndrome. J Hum Genet 46:158-162.

Johnson Jr RG (1988) Accumulation of biological amines into chromaffin granules: a model for hormone and neurotransmitter transport. Physiol Rev 68:232-307.

Kelly JP, Wrynn AS, Leonard BE (1997) The olfactory bulbectomized rat as a model of depression: An update. Pharmacol Ther 74:299-316.

Knoth J, Isaacs JM, Njus D (1981) Amine transport in chromaffin granule ghosts. $\mathrm{pH}$ dependence implies cationic form is translocated. J Biol Chem 256:6541-6543.

Kunugi H, Ishida S, Akahane A, Nanko S (2001) Exon/intron boundaries, novel polymorphisms, and association analyses with schizophrenia of the human synaptic vesicle monoamine transporter (SVMT) gene. Mol Psychiatry 6:456-460.

Lin Z, Walther D, Yu XY, Li S, Drgon T, Uhl GR (2005) SLC18A2 promoter haplotypes and identification of a novel protective factor against alcoholism. Hum Mol Genet 14:1393-1404.

Lira A, Zhou M, Castanon N, Ansorge MS, Gordon JA, Francis JH, BradleyMoore M, Lira J, Underwood MD, Arango V, Kung HF, Hofer MA, Hen R, Gingrich JA (2003) Altered depression-related behaviors and functional changes in the dorsal raphe nucleus of serotonin transporterdeficient mice. Biol Psychiatry 54:960-971.

Liu X, Gershenfeld HK (2001) Genetic differences in the tail-suspension test and its relationship to imipramine response among 11 inbred strains of mice. Biol Psychiatry 49:575-581.

Liu Y, Peter D, Roghani A, Schuldiner S, Prive GG, Eisenberg D, Brecha N, Edwards RH (1992) A cDNA that suppresses $\mathrm{MPP}^{+}$toxicity encodes a vesicular amine transporter. Cell 70:539-551.

Lucki I, Dalvi A, Mayorga AJ (2001) Sensitivity to the effects of pharmacologically selective antidepressants in different strains of mice. Psychopharmacol 155:315-322.

Maes M, Meltzer HY (1994) The serotonin hypothesis of major depression. In: Psychopharmacology: the fourth generation of progress (Bloom FE, Kupfer DJ, eds), pp 813-822. New York, Raven.

Mahata SK, Mahata M, Fisher-Colbrie R, Winkler H (1993) Vesicle monoamine transporter 1 and 2: differential distribution and regulation of their mRNAs in chromaffin and ganglionic cells of rat adrenal medulla. Neurosci Lett 156:70-72.

Maier SF, Watkins LR (2005) Stressor controllability and learned helplessness: the roles of the dorsal raphe nucleus, serotonin, and corticotropinreleasing factor. Neurosci Biobehav Rev 29:829-841.

Merali Z, Levac C, Anisman H (2003) Validation of a simple, ethologically relevant paradigm for assessing anxiety in mice. Biol Psychiatry 54:552-565.
Miller GW, Gainetdinov RR, Levey AI, Caron MG (1999) Dopamine transporters and neuronal injury. Trends Phamacol Sci 20:424-429.

Monteggia LM, Luikart B, Barrot M, Theobold D, Malkovska I, Nef S, Parada LF, Nestler EJ (2006) Brain-derived neurotrophic factor conditional knockouts show gender differences in depression-related behaviors. Biol Psychiatry 61:187-197.

Overstreet DH (1993) The Flinders sensitive line rats: a genetic animal model of depression. Neurosci Biobehav Rev 17:51-68.

Peter D, Jimenez J, Liu Y, Kim J, Edwards RH (1994) The chromaffin granule and synaptic vesicle amine transporters differ in substrate recognition and sensitivity to inhibitors. J Biol Chem 269:7231-7237.

Peter D, Liu Y, Sternini C, de Giorgio R, Brecha N, Edwards RH (1995) Differential expression of two vesicular monoamine transporters. J Neurosci 15:6179-6188.

Pogorelov VM, Rodriguiz RM, Insco ML, Caron MG, Wetsel WC (2005) Novelty seeking and stereotypic activation of behavior in mice with disruption of the Dat1 gene. Neuropsychopharmacology 30:1818-1831.

Porsolt RD, Le Pechon M, Jalfre M (1977) Depression: a new animal model sensitive to antidepressant treatments. Nature 266:730-732.

Pothos EN, Larsen KE, Krantz DE, Liu Y, Haycock JW, Setlik W, Gershon MD, Edwards RH, Sulzer D (2000) Synaptic vesicle transporter expression regulates vesicle phenotype and quantal size. J Neurosci 20:7297-7306.

Rau KS, Birdsall E, Hanson JE, Johnson-Davis KL, Carroll FI, Wilkins DG, Gibb JW, Hanson GR, Fleckenstein AE (2005) Bupropion increases striatal vesicular monoamine transport. Neuropharmacology 49:820-830.

Rehavi M, Goldin M, Roz N, Weizman A (1998) Regulation of rat brain vesicular monoamine transporter by chronic treatment with ovarian hormones. Mol Brain Res 57:31-37.

Ridder S, Chourbaji S, Hellweg R, Urani A, Zacher C, Schmid W, Zink M, Hörtnagl H, Flor H, Henn FA, Schütz G, Gass P (2005) Mice with genetically altered glucocorticoid receptor expression show altered sensitivity for stress-induced depressive reactions. J Neurosci 25:6243-6250.

Riddle EL, Topham MK, Haycock JW, Hanson GR, Fleckenstein AE (2002) Differential trafficking of the vesicular monoamine transporter- 2 by methamphetamine and cocaine. Eur J Pharmacol 449:71-74.

Rusnák M, Kretňanský, Jeloková J, Palkovits M (2001) Effect of novel stressors on gene expression of tyrosine hydroxylase and monoamine transporters in brainstem noradrenergic neurons of long-term repeatedly immobilized rats. Brain Res 899:20-35.

Schatzberg AF, Garlow SJ, Nemeroff CB (2002) Molecular and cellular mechanisms in depression. In: Neuropsychopharmacology: the fifth generation of progress (Davis KL, Charney D, Coyle JT, Nemeroff C, eds), pp 1039-1050. Philadelphia: Lippincott Williams and Wilkins.

Schildkraut JJ (1965) The catecholamine hypothesis of affective disorders: a review of supporting evidence. Am J Psychiatry 122:509-522.

Schramm NL, McDonald MP, Limbird LE (2001) The $\alpha_{2 \mathrm{~A}}$-adrenergic receptor plays a protective role in mouse behavioral models of depression and anxiety. J Neurosci 21:4875-4882.

Schwartz K, Yadid G, Weizman A, Rehavi M (2003) Decreased limbic vesicular monoamine transporter 2 in a genetic rat model of depression. Brain Res 965:174-179.

Shanks N, Anisman H (1989) Strain-specific effects of antidepressants on escape deficits induced by inescapable shock. Psychopharmacol 99:122-128.

Shepherd JK, Grewal SS, Fletcher A, Bill DJ, Dourish CT (1994) Behavioural and pharmacological characterization of the elevated "zero-maze" as an animal model of anxiety. Psychopharmacology 116:56-64.

Steru L, Chermat R, Thierry B, Simon P (1985) The tail suspension test: a new method for screening antidepressants in mice. Psychopharmacology 85:367-370.

Sulzer D, Rayport S (1990) Amphetamine and other psychostimulants reduce $\mathrm{pH}$ gradients in midbrain dopaminergic neurons and chromaffin granules: a mechanism of action. Neuron 5:797-808.

Surratt CK, Persico AM, Yang XD, Edgar SR, Bird GS, Hawkins AL, Griffin CA, Li X, Jabs EW, Uhl GR (1993) A human synaptic vesicle monoamine transporter cDNA predicts posttranslational modifications, reveals chromosome 10 gene localization and identifies TaqI RFLPs. FEBS Lett 318:325-330.

Takahashi N, Miner LL, Sora I, Ujike H, Revay RS, Kostic V, Jackson-Lewis V, Przedborski S, Uhl GR (1997) VMAT2 knockout mice: heterozygotes display reduced amphetamine-conditioned reward, enhanced amphetamine locomotion, and enhanced MPTP toxicity. Proc Natl Acad Sci USA 94:9938-9943. 
Treit D, Fundytus M (1988) Thigmotaxis as a test for anxiolytic activity in rats. Pharmacol Biochem Behav 31:959-962.

Vilpoux C, Leroux-Nicollet I, Naudon L, Raisman-Vozari R, Costentin J (2000) Reserpine or chronic paroxetine treatments do not modify the vesicular monoamine transporter 2 expression in serotonin-containing regions of rat brain. Neuropharmacology 39:1075-1082.

Wagner HR, Hall TL, Cote IL (1977) The applicability of inescapable shock as a source of animal depression. J Gen Psychol 96:313-318.

Wang YM, Gainetdinov RR, Fumagalli F, Xu F, Jones SR, Bock CB, Miller GW, Wightman RM, Caron MG (1997) Knockout of the vesicular monoamine transporter 2 gene results in neonatal death and supersensitivity to cocaine and amphetamine. Neuron 19:1285-1296.

Wei Q, Lu XY, Liu L, Schafer G, Shieh KR, Burke S, Robinson TE, Watson SJ, Seasholtz AF, Akil H (2004) Glucocorticoid receptor overexpression in forebrain: a mouse model of increased emotional lability. Proc Natl Acad Sci USA 101:11851-11856.

Weiss JM, Cierpial MA, West CH (1998) Selective breeding of rats for high and low motor activity in a swim test: toward a new animal model of depression. Pharmacol Biochem Behav 61:49-66.
Xu F, Gainetdinov RR, Wetsel WC, Jones SR, Bohn LM, Miller GW, Wang YM, Caron MG (2000) Supersensitivity to psychostimulants in mice lacking the noradrenaline transporter. Nat Neurosci 3:465-471.

Zimmerman M, Chelminski I, McDermut W (2002) Major depressive disorder and axis I diagnostic comorbidity. J Clin Psychiatry 63:187-193.

Zubieta J-K, Huguelet P, Ohl LE, Koeppe RA, Kilbourn MR, Carr JM, Giordani BJ, Frey KA (2000) High vesicular monoamine transporter binding in asymptomatic bipolar I disorder: sex differences and cognitive correlates. Am J Psychiatry 157:1619-1628.

Zucker M, Weizman A, Harel D, Rehavi M (2001) Changes in vesicular monoamine transporter (VMAT2) and synaptophysin in rat substantia nigra and prefrontal cortex induced by psychotropic drugs. Neuropsychobiology 44:187-191.

Zucker M, Aviv A, Shelef A, Weizman A, Rehavi M (2002) Elevated platelet vesicular monoamine transporter density in untreated patients diagnosed with major depression. Psychiatry Res 112:251-256.

Zucker M, Weizman A, Rehavi M (2005) Repeated stress leads to downregulation of vesicular monoamine transporter 2 in rat brain nucleus accumbens and striatum. Eur Neuropsychopharmacol 15:199-201. 